\title{
O RENDIMENTO ESCOLAR DA CRIANÇA E DO ADOLESCENTE VÍTIMAS DE VIOLÊNCIA DOMÉSTICA
}

\author{
THE SCHOOL PERFORMANCE OF CHILDREN AND TEENAGERS VICTIMS OF \\ SCHOOL SCHOOL PERFORMANCE OF CHILDREN AND TEENAGERS VICTIMS OF \\ DOMESTIC VIOLENCE OF
}

\author{
Aline Gabriela de Souza ${ }^{\mathrm{I}}$ \\ Caroline Pazini Lima Trevizan ${ }^{2}$ \\ Sileno Marcos Araújo Ortin ${ }^{3}$ \\ Tiago Moreno Lopes Roberto 4
}

RESUMO: O presente estudo analisou a concepção da violência doméstica contra crianças e adolescentes e seu desempenho na aprendizagem escolar através dos parâmetros avaliativos e, além disso, descreve como estes tipos de violências podem influenciar na mudança do comportamento da criança e do adolescente. O estudo busca identificar crianças com baixo rendimento escolar e a concepção dos educadores sobre o referido fenômeno e descrever como avaliam o rendimento escolar daqueles que são vítimas da violência doméstica. Além disso, os resultados sugerem que os sinais de violência doméstica quando são apresentados pela criança em sala de aula devem servir de alerta para que os educadores saiam da neutralidade e mantenham uma relação de respeito e confiança com a criança ou adolescente e procure medidas afetivas. Portanto existem fatores que contribuem ara que essas práticas de violência ocorram, dentre as quais destacamos: as relações de poder e de gênero predominante nas sociedades; as características do agressor e da vítima, as questões culturais, ausência de mecanismos seguros, conflitos e o medo de denunciar tendo em vista a ineficiência dos órgãos competentes, a certeza da impunidade, entre outros. Esse levantamento de dados pretende

\footnotetext{
${ }^{1}$ Pedagoga (Faculdade Futura)

2 Pedagoga (Faculdade Futura)

3 Graduado em Administração (UNIFEV), Especialista em Marketing, Recursos Humanos e Gerência (UNIFEV), Especialista em Programa de Implementação e Gestão em Educação à Distância (UFF), Coordenador de curso de Administração, Mestre em Ciências Ambientais (UNIVERSIDADE BRASIL)

${ }_{4}$ Graduado em Psicologia (UNIFEV), Especialista em saúde mental (FUTURA), Mestre em Psicologia e Saúde (FAMERP), Gestor de Políticas Acadêmicas (FUTURA), Professor do curso de Psicologia (UNIRP).tiago.moreno@faculdadefutura.com.br
} 
analisar vivências práticas que fazem parte do contexto a ser estudado. Será utilizado como instrumento de coleta de dados um questionário semiestruturado que será aplicado com professores e alunos da unidade escolar.

Palavras-chave: Violência doméstica. crianças e adolescentes. rendimento escolar.

ABSTRACT: This study aims to address the concept of domestic violence against children and adolescents and their performance in school learning through evaluative parameters and, in addition, describe how these types of violence can influence the change in the behavior of children and adolescents. It is intended to identify the most "common" types of domestic violence and their consequences, thus observing how a conflicting family environment directly affects the child's mind in a large proportion, contributing to school failure. The violence suffered by a child at home and its aggravating factors in the classroom, with the aim of showing and alerting, so that educators come out of neutrality when they realize that a student is being a victim of violence, maintaining a respectful and trusting relationship with the child. children and adolescents and to seek affective measures to ensure fundamental rights. The factors that contribute to this practice being observed and maintained, among which we highlight: the power and gender relations prevalent in societies, the characteristics of the aggressor and the victim, cultural issues, absence of safe mechanisms and conflicts, fear to denounce the inefficiency of the assistance agencies and the certainty of impunity among others. This data collection intends to analyze practical experiences that are part of the context to be studied. A semistructured questionnaire will be used as a data collection instrument to be applied with teachers and students of the school unit.

Keywords: Domestic violence. children and adolescents. school performance.

\section{INTRODUÇÃO}

Atualmente existem várias formas de violência, por exemplo: o preconceito, as agressões físicas e verbais, o bullying a homofobia e, dessa maneira, todos esses tipos de violência podem envolver direta ou indiretamente as crianças e adolescentes.

A violência doméstica, por exemplo, pode influenciar na mudança de comportamento da criança e do adolescente e, dessa forma, pode causar o declínio na escola devido aos transtornos psicológicos, manifestações clínicas, dentre outras dificuldades e, muito provavelmente, levar ao fracasso escolar.

O presente estudo analisou fatores de risco que estão presentes no contexto familiar: a violência doméstica. Nesse sentido, se identificou concepções dos educadores 
sobre o referido assunto e como avaliam o rendimento escolar da criança e do adolescente que são vítimas da violência doméstica.

O desempenho escolar da criança deve ser analisado através de um relatório feito pelo professor responsável pelo aluno em questão. Considerando-se não apenas suas características pessoais, mas também seu ambiente familiar e escolar, pois ambos os contextos coabitam e interferem na cotidianidade da criança e podem facilitar ou prejudicar o aluno em suas potencialidades e habilidades.

Assim sendo, no âmbito da aprendizagem, a interação desses fatores pode contribuir tanto para o sucesso quanto para o fracasso educacional. Tal compreensão é compatível com a concepção sistêmica, na qual o baixo rendimento escolar deve ser atribuído não só às características individuais, mas também ao seu contexto familiar, escolar e social.

Enfrentar o problema da violência doméstica implica abordar a questão do sofrimento intenso que a acompanha, sempre disseminado no ambiente em que ocorre.

As consequências da violência doméstica podem ser muito sérias, pois crianças e adolescentes aprendem com cada situação que vivenciam, seu psicológico é condicionado pelo social e o primeiro grupo social que a criança e adolescente tem contato é a família. $\mathrm{O}$ meio familiar ainda é considerado um espaço privilegiado para o desenvolvimento físico, mental e psicológico de seus membros um lugar "sagrado" e desprovido de conflitos. (ROSAS; CIONEK, 2006).

A importância da escola no enfrentamento da violência doméstica e familiar fica ainda mais evidente quando se considera que crianças e adolescentes têm contato diário e prolongado com ela e com seus profissionais e quando se coloca que, em grande parte dos casos, ela se constitui na única fonte de proteção, especialmente para as crianças e adolescentes que têm familiares como agressores e não encontram, em outros membros da família, a confiança e o apoio necessários à revelação da violência (RISTUM, 20I0).

Wallon apud Maboney e Almeida (2005) defende que o processo de evolução depende tanto da capacidade biológica do sujeito quanto do ambiente, que o afeta de 
alguma forma. Ele nasce com um equipamento orgânico, que lhe dá determinados recursos, mas é o meio que vai permitir que essas potencialidades se desenvolvam.

DESENVOLVIMENTO

Em nosso referencial teórico utilizamos autores que oferecem subsídios ao nosso estudo, uma vez que a violência doméstica exige um estudo aprofundado sobre as possíveis ações que a escola deve realizar quando detecta esse tipo de situação. $O$ aluno vítima de violência precisa encontrar espaço para falar sobre isso e, dessa forma, nos parece que autores como Paulo Freire que discuti sobre a pedagogia do oprimido e Habermas que nos explica sobre a teoria do agir comunicativo, ambos autores dialógicos, nos ensinam a dialogar com o educando de forma democrática.

\section{Habermas e o conceito da ação comunicativa}

“Com o conceito de "ação comunicativa”, Habermas deseja explicitar um tipo de interação adequada ao modelo de análise do mecanismo linguístico de coordenação das ações, compreendido em termos do efeito ilocucionário obrigatório dos atos-de-fala" (ARAGÃO, 1992, p.52).

Segundo Aragão (1992, p.52), a ação comunicativa é definida como oposição a ação estratégica, visto que na ação comunicativa os participantes estão em busca de alcançar um entendimento sobre uma situação: "sobre seus planos de ação, para coordená-los através de um acordo que é obtido através de definições das situações que admitem consenso". Enquanto, a ação estratégica se opõe, visto que um dos indivíduos pretende provocar uma decisão por caminhos alternativos da ação, logo, considera os objetivos de suas intenções particulares. Portanto, a ação comunicativa exige uma interação entre os sujeitos envolvidos, logo, é uma forma de realizar entendimento e, consequentemente, coordenar as ações.

Habermas deixa claro que a linguagem só é relevante quando utilizada na ótica de uma teoria da ação comunicativa, visto que é por meio do diálogo que possibilita aos sujeitos estabelecer relações com o mundo. Ainda segundo Aragão, a construção da teoria da ação comunicativa de Habermas: 
[...] parte de uma ontologia onde existem sujeitos-atores dotados de capacidade linguística, e três mundos com os quais estes se relacionam, a saber, o mundo objetivo (com a totalidade de entidades sobre as quais são possíveis afirmações verdadeiras), o mundo social (como a totalidade de relações interpessoais legitimamente reguladas) e o mundo subjetivo (como a totalidade de experiências à qual o falante tem um acesso privilegiado e que pode expressar ante um público). (ARAGÃO, 1992, p.53).

Portanto, a ação comunicativa visa "alcançar entendimento", tem como perspectiva um processo de interpretação cooperativo, e, além disso, deve estabelecer relações com o mundo num processo cooperativo de interpretação que os atores que participam dessas ações se relacionam simultaneamente com algo no mundo objetivo, social e subjetivo (HABERMAS, 1987 apud ARAGÃO, 1992, p.54).

Ao considerar a ação comunicativa como forma de mecanismo da coordenação das ações entre os sujeitos, "na intersubjetividade do entendimento linguístico" dos participantes, encontra-se total ausência de coerção, visto que o posicionamento de cada um dos sujeitos poderá ser contestado pelos demais, de maneira que justifique a validade de seu posicionamento sem fazer o uso da força. Portanto, cada um assume o potencial de racionalidade em seu posicionamento, logo, vence o posicionamento que apresente os melhores argumentos (ARAGÃO, 1992, p.54).

[...] a ação comunicativa se torna uma maneira de combater o dogmatismo, a dominação social, enfim, qualquer forma de coação interna ou externa imposta aos sujeitos falantes e agentes. Ela não só combate a dominação como também promove a emancipação de todas as formas de dominação social (ARAGÃ̃, 1992, p.55).

Diante das leituras realizadas, percebe-se que a ação comunicativa proposta por Habermas estabelece uma perspectiva democrática para a solução de conflitos que envolvem os sujeitos nas diversas questões do cotidiano. Portanto, por meio do diálogo o sujeito consegue rever as suas condutas, atitudes, argumentos e, deste modo, melhora as suas relações interpessoais, logo, evolui em busca da própria emancipação. 


\section{Oprimidos em busca da superação}

Diante dos escritos da obra 'Pedagogia do Oprimido' percebe-se que o autor menciona a existência de uma contradição entre os opressores e oprimidos. Freire considera que a violência causada pelos opressores os torna sujeitos desumanizados. E explica que "como distorção do ser mais, o ser menos leva os oprimidos, cedo ou tarde, a lutar contra quem os fez menos" (FREIRE, 2013, p.28).

Segundo Freire (2013), para que essa luta dos oprimidos tenha sentido, não pode ocorrer essa contradição entre as duas posições sociais. Os oprimidos não devem reproduzir as ações que sofreram de seus opressores, para que, ao buscar a recuperação de sua humanidade, não sejam opressores dos opressores, "mas restauradores da humanidade em ambos"

E aí está a grande tarefa humanista e histórica dos oprimidos - libertar-se a si e aos opressores. Estes, que oprimem, exploram e violentam, em razão de seu poder, não podem ter, neste poder, a força de libertação dos oprimidos nem de si mesmos. Só o poder que nasça da debilidade dos oprimidos será suficientemente forte para libertar a ambos. Por isto é que o poder dos opressores, quando se pretende amenizar ante a debilidade dos oprimidos, não apenas quase sempre se expressa em falsa generosidade, como jamais a ultrapassa. Os opressores, falsamente generosos, têm necessidade, para que a sua "generosidade" continue tendo oportunidade de realizar-se, da permanência da injustiça. A "ordem" social injusta é a fonte geradora, permanente, desta "generosidade" que se nutre da morte, do desalento e da miséria (FREIRE, 2013, p.28).

Encontra-se presente nessa obra uma importante contribuição para o debate educacional e, além disso, amplia a visão de mundo do sujeito, encorajando-o a buscar o seu pleno desenvolvimento enquanto ser humano. Visto que vivemos em sociedade, e que muitas vezes somos oprimidos devido a nossa posição social. A partir das leituras realizadas, é possível compreender que somente poderemos superar essa posição de sujeito oprimido por meio do conhecimento, portanto, temos que reconhecer a necessidade de lutar e agir pela nossa libertação. Diante disso Freire afirma que:

Quem, melhor que os oprimidos, se encontrará preparado para entender o significado terrível de uma sociedade opressora? Quem sentirá, melhor que eles, os efeitos da opressão? Quem, mais que eles, para ir 
compreendendo a necessidade da libertação? Libertação a que não chegarão pelo acaso, mas pela práxis de sua busca; pelo conhecimento e reconhecimento da necessidade de lutar por ela (FREIRE, 2013, p.29).

Seguindo essa lógica de opressores e oprimidos, encontra-se presente nas relações escolares, a exemplo disso, a concepção bancária da educação como um instrumento da opressão. "Há uma quase enfermidade da narração. A tônica da educação é preponderante esta - narrar, sempre narrar". Diante dessa situação, o professor atua como um indiscutível agente, cuja tarefa é "encher" os educandos dos conteúdos de sua narração. Deste modo, "a educação se torna um ato de depositar, em que os educandos são os depositários e o educador o depositante" (FREIRE, 2013, p.54).

É indiscutível que, se pretendemos promover a libertação das pessoas, a educação não pode alienar, pelo contrário, a libertação autêntica faz parte do processo de humanização, logo, é por meio da própria ação e reflexão do ser sobre o mundo, que será possível transformá-lo. Portanto, não podemos aceitar a educação do depósito de conteúdos, mas aquela que problematiza e considera o sujeito crítico e reflexivo diante das relações com o mundo, a educação libertadora (FREIRE, 2013).

Encontra-se na sequência os escritos sobre a dialogicidade da educação, assim sendo, um propósito de educação problematizadora, logo, é indispensável fazer considerações sobre a essência do diálogo. Considerações essas que estão compartilhadas com o tema de educação como prática da liberdade. Portanto, "não é no silêncio que os homens se fazem, mas na palavra, no trabalho, na ação-reflexão” (FREIRE, 2013, p.72).

Nosso papel não é falar ao povo sobre a nossa visão de mundo, ou tentar impô-la a ele, mas dialogar com ele sobre a sua e a nossa. Temos de estar convencidos de que a sua visão do mundo, que se manifesta nas várias formas de sua ação, reflete a sua situação no mundo, em que se constitui. A ação educativa e política não pode prescindir do conhecimento crítico dessa situação, sob pena de se fazer "bancária" ou de pregar no deserto (FREIRE, 2013, p.78).

\section{A violência doméstica e os reflexos no ambiente escolar}

De acordo com Brito et al. (2005) a violência doméstica contra crianças e adolescentes é um fenômeno que existe há muitos anos, desde a antiguidade. No entanto, 
foi a partir da década de 80 que passou a ser mais estudada pela comunidade científica. Entretanto, cabe ressaltar que existe uma carência de políticas públicas eficazes para a criação e manutenção de programas preventivos no combate a esses problemas.

As modalidades de violência doméstica são classificadas em:

(...) violência física, violência psicológica, negligência e violência sexual. Essas modalidades podem ocorrer na forma pura, quando se trata de uma única modalidade de violência, ou associada, quando em um mesmo caso são identificadas duas ou mais modalidades (BRITO et al. 2005, p. I45).

O estatuto da criança e do adolescente dispõe sobre a proteção integral à criança e ao adolescente e, no artigo $5^{\circ}$, define direitos fundamentais:

Nenhuma criança ou adolescente será objeto de qualquer forma de negligência, discriminação, exploração, violência, crueldade e opressão, punido na forma da lei qualquer atentado, por ação ou omissão, aos seus direitos fundamentais (BRASIL, 1990, p. 05).

Diante disso, a escola e, especialmente os professores, não podem se omitir diante dos casos de violência doméstica, uma vez que isso pode interferir negativamente nos processos de aprendizagem da criança ou adolescente. Nesse sentido, ao considerar os direitos de aprendizagem da criança, o professor deve assegurar que a criança ou o adolescente não sofra prejuízos de aprendizagem.

Art. $4^{o}$ É dever da família, da comunidade, da sociedade em geral e do poder público assegurar, com absoluta prioridade, a efetivação dos direitos referentes à vida, à saúde, à alimentação, à educação, ao esporte, ao lazer, à profissionalização, à cultura, à dignidade, ao respeito, à liberdade e à convivência familiar e comunitária (BRASIL, 1990, p. 07).

Existem estudos que apontam sobre o perfil de alunos que mais sofrem algum tipo de violência. Esses dados podem ser aproveitados pela escola para orientar professores e demais funcionários a ficarem mais atentos com as crianças e adolescentes que estão no grupo mais afetado.

De acordo com o estudo de Silva, Azambuja e Santana (2015), que analisaram 282 crianças entre seis e dezessete anos de idade com histórico de maus tratos, foi possível conhecer o perfil das crianças e adolescentes vítimas de algum tipo de violência doméstica. 
O estudo aponta que a idade média é de io,6 anos de idade e a maior parte são do sexo feminino e estudantes de escolas públicas. Além disso, 34,1\% das crianças e adolescentes já foram reprovados em alguma etapa escolar e 44,2\% demonstraram dificuldades de aprendizagem.

Outra característica importante é o perfil da família das vítimas, que também pode ser um fator de alerta para os professores.

Silva, Azambuja e Santana (2015) apontam em seu estudo que, 60,8\% dos participantes são frutos de uma gravidez não planejada e que a maior parte das crianças ou adolescentes são de pais separados. Além disso, fatores como a renda da família também foram representativos no grupo de crianças e adolescentes que foram investigados pelo estudo.

Diante disso, todas as características que foram mencionadas poderão servir de alerta aos professores e demais profissionais envolvidos no atendimento de crianças e adolescentes.

\section{PROCEDIMENTOS METODOLOGICOS}

Inicialmente construímos um referencial teórico de estudos publicados no campo acadêmico que pudessem contribuir com a nossa questão de pesquisa. Após essa ampla revisão da literatura, realizamos uma investigação por meio de pesquisa de campo em escolas públicas e privadas de ensino infantil, fundamental I e fundamental II. Esse levantamento de dados analisou vivências práticas que fazem parte do contexto estudado. Utilizamos como instrumento de coleta de dados um questionário semiestruturado que foi aplicado com professores e alunos da unidade escolar.

De acordo com Indalécio (2015, p. 9o) esse instrumento pode "permitir o acesso a um maior número de elementos, favorecendo a sistematização da coleta e gestão das informações, e também porque comporta uma metodologia rigorosa e um tratamento homogêneo dos dados".

Os participantes desse estudo são professores e alunos de uma escola da rede municipal de Votuporanga/SP. Foi utilizada, prioritariamente, a abordagem qualitativa e, 
também, de natureza quantitativa. A população de pesquisa foi constituída por professores que atuam no ensino infantil, fundamental I e fundamental II e dos respectivos alunos que possuem faixa etária entre três e dezessete anos.

Essa investigação buscou responder a nossa questão principal: quais as implicações da violência doméstica nos processos de ensino e aprendizagem infantil?

Os procedimentos de análise dos dados são predominantemente qualitativos. Entretanto, para analisar os dados que foram coletados por meio dos questionários semiestruturados foi utilizada a análise estatística dos dados. Essa análise permitiu a seleção dos sujeitos que, possivelmente, poderiam contribuir com o nosso estudo.

Primeiramente, fizemos contatos com escolas da rede pública municipal da cidade de Votuporanga-SP. Por meio de um ofício fizemos o primeiro contato de maneira informal para verificar a possibilidade de uma reunião para a apresentação do estudo. Em seguida, agendamos uma reunião que foi determinada pela direção da escola com horário, local, tempo disponível, participantes, etc. Na ocasião, explicamos a intenção da pesquisa, suas fases de investigação e como ocorreria a participação dos sujeitos envolvidos. Depois formalizamos por meio de ofício esse contato inicial deixando bem esclarecido sobre os objetivos da pesquisa.

Para analisar os dados qualitativos provenientes dos questionários, fizemos a redução dos dados que segundo Gil (2002) consiste em "processo de seleção, simplificação, abstração e transformação dos dados originais provenientes das observações de campo", portanto, essa redução é utilizada para selecionar os dados que possam ser significativos para a pesquisa. Realizamos também a categorização dos dados, o que segundo Gil (2002) essa etapa "consiste na organização dos dados de forma que o pesquisador consiga tomar decisões e tirar conclusões a partir deles".

Outra etapa foi a interpretação dos dados. Nessa etapa buscamos ampliar os questionamentos existentes sobre o assunto a ser investigado. Para Gil (2002) nessa etapa da pesquisa é preciso "um esforço de abstração, ultrapassando os dados, tentando possíveis explicações, configurações e fluxos de causa e efeito”. 


\section{RESULTADOS}

Tabela r:Tabulação de dados

\begin{tabular}{|c|c|c|c|c|c|c|c|c|c|c|c|c|c|}
\hline Pesq & $Q 1$ & Q2 & Q3 & Q4 & Q5 & Q6 & Q7 & 08 & $Q 9$ & Q10 & Q11 & Q12 & Q13 \\
\hline$P 1$ & $P B$ & Ef & NÃO & SSERTATV & Sim & Ambas & Sim & Boa parte do tempo & Não & Dif. interagir social & Não & DSSSERTATVA & DISSERTATIVA \\
\hline$P 2$ & $P R$ & Ef & SIM & SSERTATV & Não & Ambass & Sim & Boaparte do tempo & Sim & Indisciplina & Não & DISSERTATIVA & DISSERTATINA \\
\hline P3 & $P B$ & $E$ & NÃO & SSERTATV & Não & Verbal & Sim & Sim, todomomento & Sim & Dif. Aprend & Não & DISSERTATVA & DISSERTATINA \\
\hline P4 & $P B$ & $E$ & SIM & SSERTATIV & Sim & F'isica & Sim & Boa parte do tempo & Sim & Indisciplina & Sim & DSSSERTATIVA & DISSERTATINA \\
\hline P5 & $P B$ & Ef & SIM & SSERTATV & Não & Ambas & Sim & Sim, todomomento & Sim & Dif. interagirsocial & Não & DISSERTATVA & DISSERTATINA \\
\hline PG & $P R$ & Ef & NÃO & SSERTATV & Sim & Ambas & Sim & Boa parte do tempo & Sim & Indisciplina & Não & DISSERTATVA & DISSERTATINA \\
\hline$P 7$ & $P R$ & Ef & SIM & SSERTATV & Não & Ambas & Sim & Sim, todomomento & Sim & Indiscipina & Não & DISSERTATVA & DISSERTATINA \\
\hline p8 & $P B$ & Ef & SIM & SSERTATV & Sim & Ambas & Sim & Sim, todomomento & Não & Indisciplina & Não & DISSERTATIVA & DISSERTATINA \\
\hline$p g$ & $P B$ & $E$ & SIM & SSERTATV & Sim & Ambas & Sim & Boa parte do tempo & Sim & Indisciplina & Sim & DISSERTATIVA & DISSERTATINA \\
\hline P10 & $P B$ & Ef & SIM & SSERTATV & Não & Ambas & Sim & Boa parte do tempo & Sim & Indisciplina & Não & DSSEETATIVA & DISSERTATIVA \\
\hline P11 & $P B$ & $E$ & SIM & SSERTATV & Sim & Ambas & Sim & Sim, todo momento & Sim & Indisciplina & Não & DISSEETATIVA & DISSERTATINA \\
\hline P12 & $P B$ & $E$ & SIM & SSERTATV & Sim & F'́sica & Sim & Boa parte do tempo & Nã̃o & Teimosia & Não & DISSERTATVA & DISSERTATINA \\
\hline$P 13$ & $P B$ & Ef & SIM & SSERTATV & Não & Ambass & Sim & Boaparte do tempo & Sim & Dif. interagirs sccial & Não & DISSERTATIVA & DISSERTATINA \\
\hline P14 & $P B$ & Ef & SIM & SSERTATV & Não & Ambas & Sim & Boa parte do tempo & Sim & Dif. interagir social & Sim & DSSSERTATIVA & DISSERTATIVA \\
\hline P15 & $P R$ & Ef & SIM & SSERTATIV & Sim & Ambas & Sim & Boa parte do tempo & Sim & Indisciplina & Não & DSSSERTATIVA & DISSERTATINA \\
\hline P16 & $P B$ & $E$ & SIM & SSERTATV & Sim & Ambas & Sim & Boa parte do tempo & Sim & Dif.interagirsocial & Não & DISSERTATVA & DISSERTATINA \\
\hline P17 & $P B$ & Ef & SIM & SSERTATV & Sim & F'́sica & Sim & Boa parte do tempo & Sim & Dif. interagir social & Não & DISSERTATVA & DISSERTATINA \\
\hline P18 & $P B$ & Ef & SIM & SSERTATV & Sim & Ambas & Sim & Boaparte do tempo & Não & Indiscipina & Não & DISSERTATVA & DISSERTATINA \\
\hline P19 & $P B$ & Ef & SIM & SSERTATV & Sim & Ambas & Sim & Boa parte do tempo & Não & Indisciplina & Não & DISSERTATVA & DISSERTATINA \\
\hline P2O & $P B$ & Ef & SIM & SSERTATV & Não & Física & Sim & Boa parte do tempo & Sim & Dif. interagir social & Não & DSSSERTATVA & DISSERTATIVA \\
\hline
\end{tabular}

Fonte: Pesquisa aplicada-2020

Questão I: A instituição de Ensino que você atua é?

Questão 2: Em que etapa da Educação Básica você atua?

Questão 3: Na sala em que você atua, ou já atuou, já se deparou com alguma criança ou adolescente vítima de violência doméstica?

Questão 5: As vítimas de violência estão passando por apoio psicológico?

Questão 6: Qual foi o tipo de violência esse aluno sofreu? 
Questão 7: Você percebeu alguma dificuldade na aprendizagem desse aluno

\begin{tabular}{|c|c|c|}
\hline QUESTÃO 6 & RESPOSTAS & $\%$ \\
\hline VERBAL & 1 & $5,00 \%$ \\
\hline FÍSICA & 4 & $20,00 \%$ \\
\hline AMBAS & 15 & $75,00 \%$ \\
\hline$\Sigma$ & 20 & $100,00 \%$ \\
\hline
\end{tabular}

\begin{tabular}{lcc}
\hline $\begin{array}{c}\text { QUESTÃO } \\
\mathbf{7}\end{array}$ & RESPOSTAS & $\%$ \\
\hline SIM & 20 & $100,00 \%$ \\
NÃO & 0 & $0,00 \%$ \\
\hline$\Sigma$ & $\mathbf{2 0}$ & $\mathbf{1 0 0 , 0 0 \%}$ \\
\hline
\end{tabular}
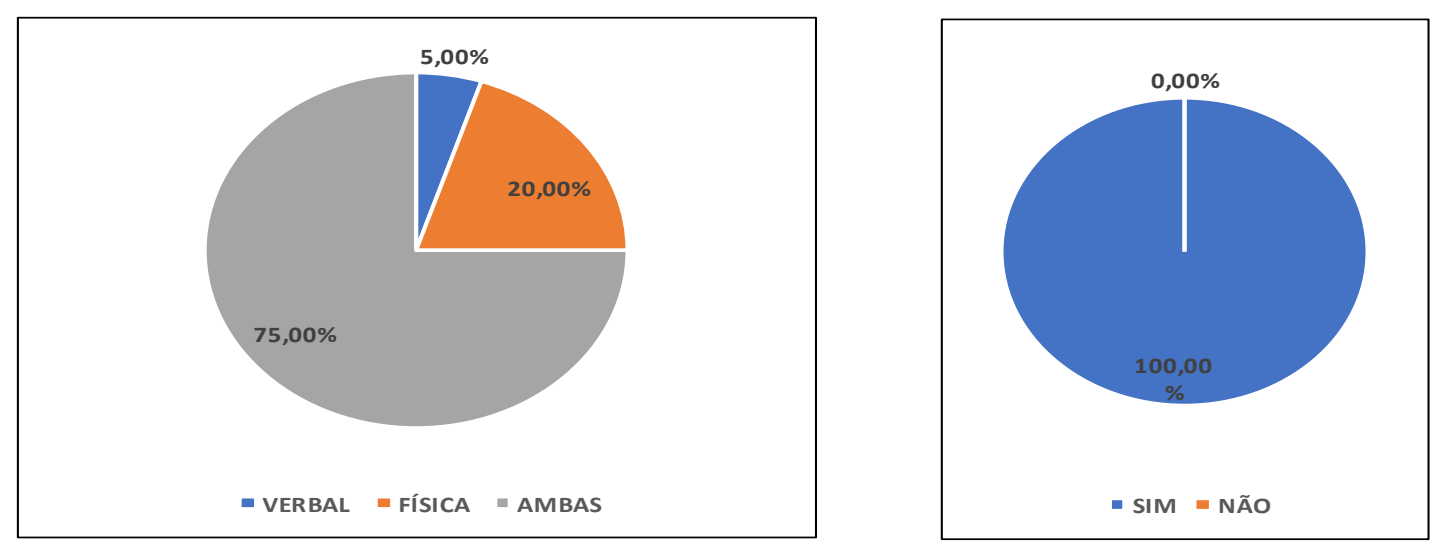

Questão 8: As vítimas apresentam comportamentos de maior dificuldade de socialização

Questão 9: As vítimas apresentam comportamentos típicos do Transtorno de Déficit de Atenção com Hiperatividade (TDAH)?

\begin{tabular}{lcc}
\hline \multicolumn{1}{c}{ QUESTÃO 8 } & RESPOSTAS & $\%$ \\
\hline Sim, todo momento & 5 & \\
Boa parte do tempo & 15 & $\mathbf{2 5 , 0 0 \%}$ \\
Não, isso não ocorre & 0 & $0,00 \%$ \\
\hline$\Sigma$ & $\mathbf{2 0}$ & $\mathbf{1 0 0 , 0 0 \%}$ \\
\hline
\end{tabular}

\begin{tabular}{lcc}
\hline $\begin{array}{c}\text { QUESTÃO } \\
\mathbf{9}\end{array}$ & RESPOSTAS & \% \\
\hline SIM & 15 & $75,00 \%$ \\
NÃO & 5 & $25,00 \%$ \\
\hline$\Sigma$ & 20 & $\mathbf{1 0 0 , 0 0 \%}$ \\
\hline
\end{tabular}
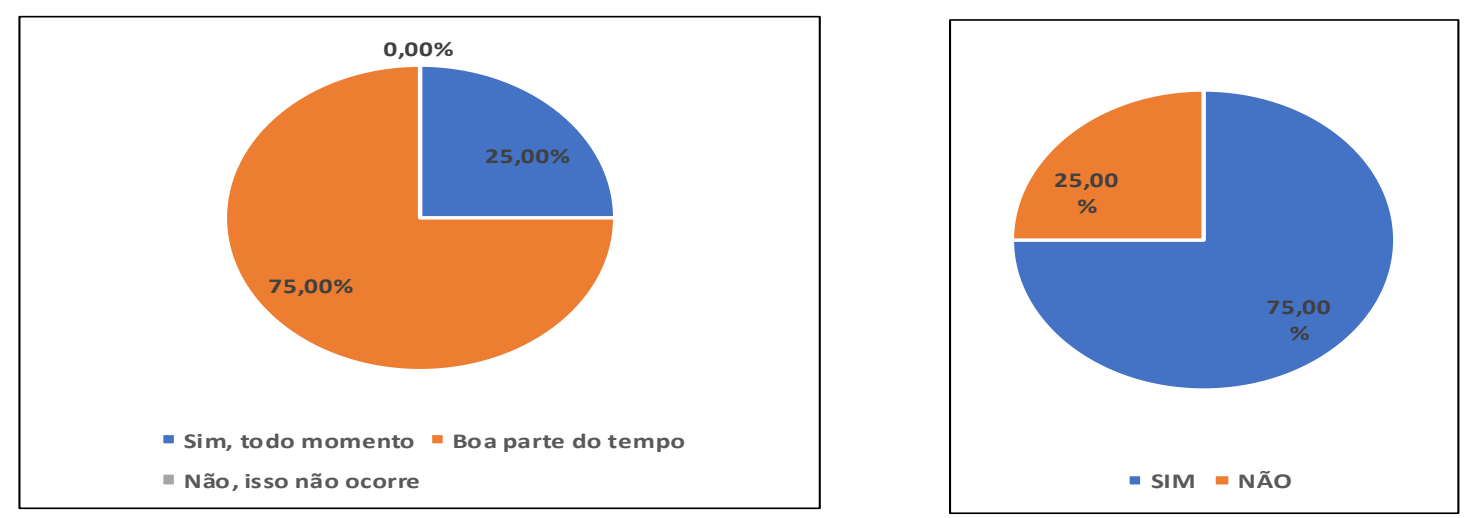

Questão ro: Qual é o comportamento desse aluno dentro e fora da sala de aula? 
Questão Ir: Teve algum caso de evasão escolar, por conta da violência doméstica?

\begin{tabular}{lcc}
\hline \multicolumn{1}{c}{ QUESTÃO 10 } & RESPOSTAS & \% \\
\hline Indisciplina & 11 & $55,00 \%$ \\
Teimosia & 1 & $5,00 \%$ \\
Dif. Interagir social & 7 & $35,00 \%$ \\
Dif. Aprend & 1 & $5,00 \%$ \\
Normal, faixa etária e demais alunc & 0 & $0,00 \%$ \\
\hline $\boldsymbol{\Sigma}$ & $\mathbf{2 0}$ & $\mathbf{1 0 0 , 0 0 \%}$ \\
\hline
\end{tabular}

\begin{tabular}{lcc}
\hline $\begin{array}{c}\text { QUESTÃO } \\
\mathbf{1 1}\end{array}$ & RESPOSTAS & \% \\
\hline SIM & 3 & $15,00 \%$ \\
NÃO & 17 & $85,00 \%$ \\
\hline$\Sigma$ & $\mathbf{2 0}$ & $\mathbf{1 0 0 , 0 0 \%}$ \\
\hline
\end{tabular}
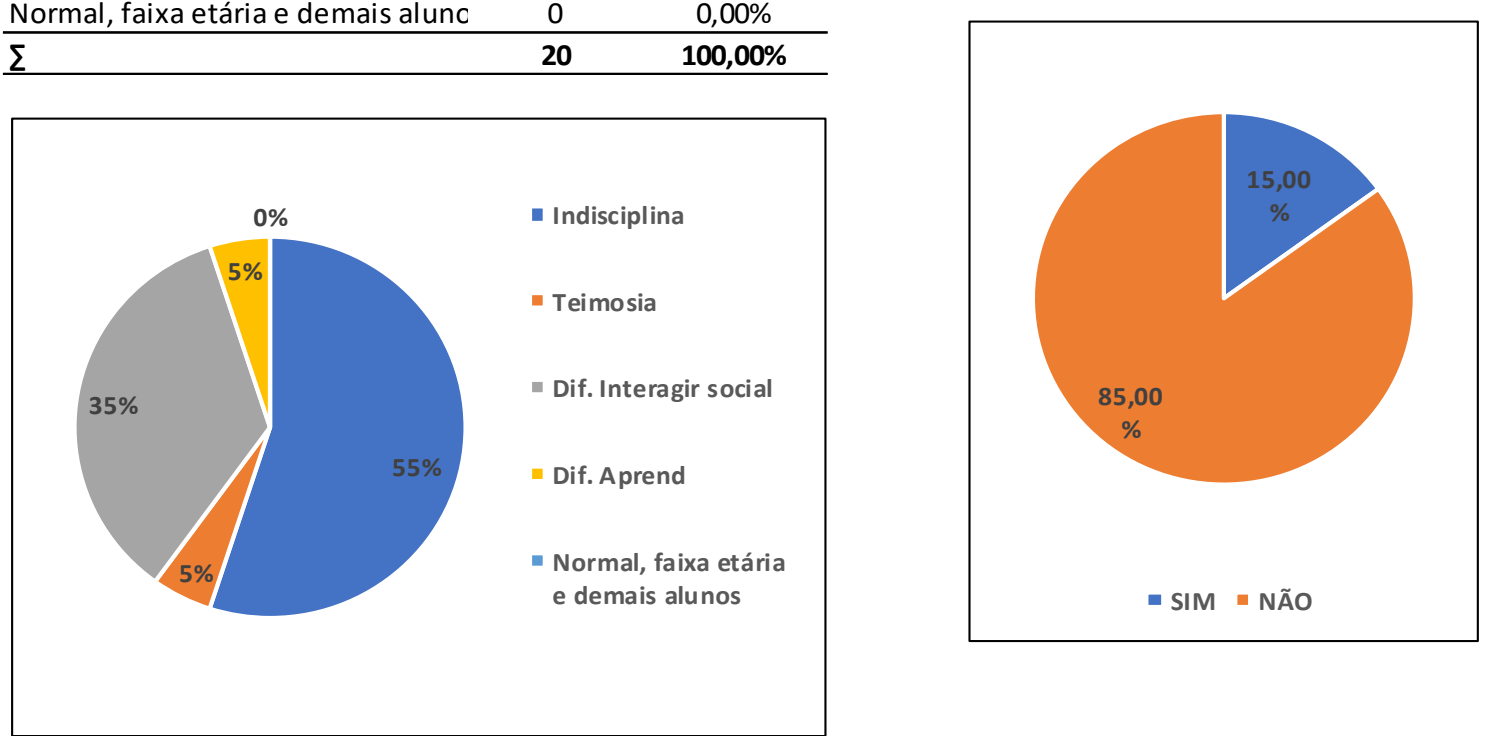

\section{DISCUSSÕES}

Com base nos Dados coletados pelos docentes podemos analisar que na primeira questão $80 \%$ dos entrevistados atuam em escola Privada enquanto 20\% atuam na escola Pública sendo assim na segunda questão 70\% dos docentes atuam no Ensino Fundamental e 30\% dos docentes atuam na Educação Infantil.

Já na terceira questão a maior porcentagem de docentes que já se depararam com alunos que sofriam ou sofre violência doméstica é de $85 \%$ enquanto $15 \%$ dos docentes não tiveram alunos com essa questão, tendo em vista que na quarta questão somente $60 \%$ dos alunos que sofrem esse tipo de violência tem apoio psicológico enquanto $40 \%$ não tem esse apoio para enfrentar a questão citada.

Analisando os tipos de violência, podemos observar que $5 \%$ dos alunos sofrem violência Verbal, 20\% dos alunos sofrem violência Física e 75\% dos alunos sofrem Ambas, 
podendo afetar muito mais a criança ou o adolescente como na sétima questão que os docentes relatam que I0o\% da aprendizagem desses alunos são afetadas.

Sendo assim 75\% dos alunos são afetados a todo momento em sua socialização enquanto $25 \%$ dos alunos são afetados em boa parte do tempo, e como visto na nona questão que $75 \%$ dos alunos apresentam comportamentos típicos de Déficit de Atenção e 25\% dos alunos não. Por tanto na décima questão relacionada ao comportamento dessas crianças $55 \%$ dos alunos são indisciplinados, $35 \%$ dos alunos tem dificuldade na interação social, $5 \%$ dos alunos são teimosos e 5\% dificuldade na aprendizagem. E na décima primeira questão relacionada a evasão escolar $85 \%$ dos anos não sofreram com isso e apenas $15 \%$ dos alunos tiveram esse problema.

\section{CONCLUSÃO}

Analisar crianças com baixo rendimento escolar e a concepção dos educadores sobre

o referido fenômeno e descrever como avaliam o rendimento escolar daqueles que são vítimas da violência doméstica.

Identificar e descrever como os alunos se comportam no ambiente escolar e qual o seu rendimento com base nas avaliações do professor em sala de aula e como o docente intervém na situação de alunos que sofrem violência doméstica e discutir como isso pode interferir na socialização desses alunos com seus pares.

\section{REFERÊNCIAS}

ARAGÃO, L. M. C. RAZÃO COMUNICATIVA E TEORIA SOCIAL CRÍTICA EM JURGEN HABERMAS. Rio de Janeiro: Tempo Brasileiro, 1992.

BRASIL. Lei no 8.069, de 13 de julho de 1990. Dispõe sobre o Estatuto da Criança e do Adolescente e dá outras providências. Diário Oficial [da] República Federativa do Brasil, Brasília, DF, i6 jul. I990. Disponível em: < 
https://www2.senado.leg.br/bdsf/bitstream/handle/id/534718/eca_Ied.pdf $>$. Acesso em: 23 Out. 2020.

BRITO, A. M. M. et al. Violência doméstica contra crianças e adolescentes: estudo de um programa de intervenção. 2005. Disponível em: < https://www.scielo.br/pdf/csc/vioni/aisvioni.pdf>. Acesso em: 23 Out. 2020.

FREIRE, P. Pedagogia do oprimido [recurso eletrônico] Rio de Janeiro: Paz e Terra, 2013. GIL, A. C. Como elaborar projetos de pesquisa. 4ed. - São Paulo: Atlas, 2002. INDALECIO, A. B. ENTRE IMIGRANTES E NATIVOS DIGITAIS: A percepção docente sobre as novas tecnologias da informação e comunicação (NTIC) e o ensino da educação física. (Dissertação de Mestrado) - Universidade Federal de São Carlos - São Carlos: UFSCar, 2015. 205 p.

MABONEY, A. A.; ALMEIDA, L. R. DE. Afetividade e processo ensino-aprendizagem: contribuições de Henri Wallon, 2005. Disponível em: < http://pepsic.bvsalud.org/pdf/psie/n2o/v20ao2.pdf >. Acesso em: 28 Nov 2019.

RISTUM, M. A violência doméstica contra crianças e as implicações da escola, 2010. Disponível em: < http://pepsic.bvsalud.org/pdf/tp/vi8nI/vi8niar9.pdf >. Acesso em: 28 Nov. 2019.

ROSAS, F. K.; CIONEK, M. I. G. D. O impacto da violência doméstica contra crianças e adolescentes na vida e na aprendizagem. Conhecimento Interativo. 2006. Disponível em: 〈https://www.mprs.mp.br/media/areas/infancia/arquivos/impacto.pdf >. Acesso em: 28 Nov. 2019.

SILVA, R. W. S.; AZAMBUJA, C. V.; SANTANA, A. Perfil de crianças e adolescentes vítimas de maus-tratos atendidos em ambulatório de psicologia da região sul do Brasil. 2015. Disponível em: < http://pepsic.bvsalud.org/pdf/aletheia/n47-48/n47-48air.pdf $>$. Acesso em: 23 Out. 2020. 